\title{
Estudo sobre 5000 Sessões de Escleroterapia com Espuma
}

\author{
Bastos FR. ${ }^{1}$ \\ ${ }^{1}$ Belo Horizonte - Brasil. \\ E-mail:drfrbastos@hotmail.com
}

Bastos, F.R. 2013. Estudo sobre 5000 Sessões de Escleroterapia com Espuma, p.52. In: Bastos, Francisco Reis. Anais do V Simpósio Internacional de Flebologia [Blucher Medical Proceedings n.1 v.1]. São Paulo: Blucher, 2014 http://dx.doi.org/10.5151/medpro-flebo-SIF_29

\section{Introdução}

A Insuficiência Venosa Crônica é doença crônica, degenerativa e aumenta com a idade. Seu controle ideal é ainda discutido ainda não sendo estabelecido qual é o ideal. (Perrin)

Entre eles, a escleroterapia constitui um método praticado há 170 anos e se renovou com a escleroterapia com espuma. O "Efeito espuma" permitiu usar menos medicamento com menos efeitos colaterais. Especialistas reunidos em congressos científicos como os Consensos de Grenoble, de Tergensee e o Club-mousse.com ajudaram a padronização do método. Os outros tipos de ablação, as térmicas, com o laser, a radiofreqüência e o vapor d água seguem sendo alternativas do controle da IVC.

\section{Material}

Esse estudo foi baseado na observação de 2875 pacientes e 5000 sessões feitas a partir de 2004. O resultado foi bom com baixo índice de complicações sendo as mais freqüentes as hiperpigmentações (nos pacientes com fototipo IV, V e VI) e os distúrbios visuais.

\section{Conclusão}

Esse estudo confirma a experiência da literatura mundial e re-afirma que o método é eficaz, econômico, seguro podendo tratar casos de IVC, além dos outros métodos cirúrgicos e não cirúrgicos.

Palavras-chave: Escleroterapia, escleroterapia com espuma, IVC, varizes, tratamento de varizes.

\section{Referências}

1. Bastos FR. Escleroterapia com Espuma. Belo Horizonte. Ed. Folium. 2012.

2. Gobin JP, Benigni JP. La sclérothérapie. Editions ESKA 2007.

3. Goldman M P. Escleroterapia. Rio de Janeiro: Interlivros; 1994. 